\title{
Porous Chitosan-silica-polyethylene Glycol Membrane for Dynamic Adsorption of Binary Mixtures Cu(II) and Zn(II) Ions
}

\author{
F. Widhi Mahatmanti, Nuryono, and Narsito
}

\begin{abstract}
The adsorption of binary mixtures of $\mathrm{Cu}(\mathrm{II})$ and Zn(II) ions was studied using dynamic methods employing chitosan-silica-polyethylene glycol $(\mathrm{Ch} / \mathrm{Si} / \mathrm{P})$ as adsorptive membrane. $\mathrm{Ch} / \mathrm{Si} / \mathbf{P}$ membrane was synthesized by blending rice hull ash (RHA) silica and polyethylene glycol into chitosan. Silica and polyethylene glycol blended into the $\mathrm{Ch}$ to improve the mechanical properties and the membrane porous. The membrane was characterized using mechanical properties test, scanning electron microscopy (SEM) and swelling test. Dynamic adsorption experiments suggested that the adsorption capacity depended on adsorbent morphology and differences concentration between the source phase and the stripping phase. $\mathrm{Ch} / \mathrm{Si} / \mathrm{P}$ membrane presented more affinity for $\mathrm{Cu}(\mathrm{II})$ than for $\mathrm{Zn}$ (II). The decrease of the amount of metal adsorbed onto $\mathrm{Ch} / \mathrm{Si} / \mathrm{P}$ membrane in binary system showed that the competition effects between two metal ions. The desorption was also investigated, $\mathrm{Cu}$ (II) and $\mathrm{Zn}$ (II) ions could be selectivity permeated using a process by water, $\mathrm{HCl}$, and Na2EDTA solution as the stripping phase.
\end{abstract}

Index Terms - Chitosan, membrane, dynamic adsorption, $\mathrm{Cu}(\mathrm{II})$ and $\mathrm{Zn}(\mathrm{II})$.

\section{INTRODUCTION}

Heavy metal contamination exists in aqueous waste streams of many industries, such as metal plating, mining operations, electroplating and pharmaceutical industry. The soil surrounding these sites is also polluted and can contaminate groundwater and surface water. Heavy metals are not biodegradable and tend to accumulate in living organisms, causing various diseases and disorders [1]-[3]. Copper and zinc pollution are of particulars concern. Copper plays an essential role in animal metabolism. it is toxic at high concentrations, with effect including vomiting, cramps, convulsions and even death [1]. Zinc is most often found in plating and galvanizing operations. In plating shops the zinc is often complexed with cyanide and the cyanide must be treated to free the zinc before precipitation can occur. Traditional cyanide destruct systems use sodium hypochlorite to oxidize the cyanide [4].

The conventional treatments used to remove heavy metals from wastewaters are precipitation, coagulation, reduction, solvent extraction, electrochemical separation through membranes, ion exchange and adsorption [1], [2], [5], [6]. These methods usually concentrate the metal ions into a

Manuscript received April 17, 2015; revised October 15, 2015.

The authors are with the Chemistry Department, Faculty of Mathematics and Natural Sciences at the Semarang State University, Indonesia (e-mail: widhimahatmanti@rocketmail.com,nuryono_mipa@ugm.ac.id). smaller volume followed by recovery or secure disposal. Recently, membrane adsorption has appeared as a powerful technique for removal of heavy metal ions from effluents [6], [7]. Compared to the conventional methods e.g. chemical precipitation, ion exchange and adsorption columns, adsorptive membranes offer several advantages for separation of heavy metals such excellent removal efficiency, high flow rate, low pressure drop, faster kinetic, reusability, smaller footprint and easy of scale up [1]-[3].

Chitosan, (1, 4)-[2-amino-2-deoxy-D-glucose] was a natural biopolymer derivative obtained from the partial deacetylation of chitin. Therefore, chitosan has amine side functional groups which are responsible for the poly-cationic character and the formation of well-known intermolecular complexes with carboxyclic and polycarboxyclic acids. In addition, it is a desirable polymer in chemical and biomedical fields due to its biodegradable performance [3], [7], [8]. The membrane prepared by chitosan plays an important role in the separation and recovery of heavy metal ions, because of it inexpensive, simple and biodegradable nature which could be used for the majority of heavy metal ion forms. However, the scope of preparing pure chitosan membrane has been largely limited due to the poor mechanical strength and chemical stability of chitosan [8]. To improve the mechanical strength, blending chitosan with silica and PEG has been found to be an effective way to overcome the problem, because blending, especially at the microscopic level through chemical interactions, could provide chitosan with the desired mechanical strength and chemical stability [8], [9].

The aim of this study was compare the adsorption and desorption behavior of binary mixture $\mathrm{Cu}(\mathrm{II})$ and $\mathrm{Zn}$ (II) ions onto $\mathrm{Ch} / \mathrm{Si} / \mathrm{P}$ membrane. Desorption experiments were performed in one step, using water, $\mathrm{HCl}$, and $\mathrm{Na}_{2}$ EDTA solution, with the objective of permeating selectivity these species.

\section{EXPERIMENTAL SECTION}

\section{A. Materials and Methods}

\section{1) Materials}

Chitosan was purchased from CV Ocean Fresh Bandung with a molecular weight, determined through viscometer method, of $8.78 \mathrm{kDa}$. All other chemicals (acetic acid, sodium hydroxide, hydrochloric acid, PEG, copper nitrate, zinc nitrate) were of analytical grade used without further purification. The solution was prepared used deionized water. 
Sodium silicate $\left(25 \% \mathrm{SiO}_{2}\right)$ was obtained from extraction rice hull ash.

\section{2) Instruments}

The membrane cell consists of cylindrical chamber that is separated into two halves by membrane Ch/Si/P (Fig. 1) [10], the effective volume of each chamber was $50 \mathrm{~mL}$ and the effective diameter of membrane was $2.5 \mathrm{~cm}$. Atomic absorption spectroscopy/AAS (Perkin- Elmer AA200) was applied for determination of metal ions concentration in the sample solution.

- Feed solution phase

- Magnetic stirrer

- Stripping solution phase

- Membrane Ch/Si/P

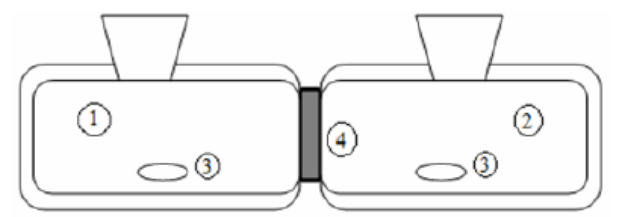

Fig. 1. Experimental set-up.

\section{B. Preparation of Chitosan-silica-PEG Membrane} $(\mathrm{Ch} / \mathrm{Si} / \mathrm{P})$

A silica and PEG blended chitosan membrane (Ch/Si/P) was prepared by mixing $1.0 \mathrm{~g}$ chitosan solution containing in $100 \mathrm{~mL}$ of $2 \mathrm{vol} \%$ acetic acid solution, mixing $0.8 \mathrm{~g}$ of rice hull ash sodium silicate solution and $0.5 \mathrm{~g}$ PEG were mixed with the chitosan solution. The mixture was thoroughly stirred until there was no air bubble in the solution. Membrane was obtained by casting the mixture on a glass plate and was allowed to evaporate the solvent under an ambient temperature for 3 days. Membrane was neutralized with a $5 \%(\mathrm{w} / \mathrm{v}) \mathrm{NaOH}$ solution after drying. Afterward, the membrane was washed with water to remove the remaining $\mathrm{NaOH}$. Finally, the membrane was characterized using mechanical properties test, SEM and swelling test.

\section{Dynamic Adsorption Experiments}

Binary component adsorption. The aqueous feed solution was prepared by dissolving metal ions in deionized water at concentration $25 \mathrm{mg} / \mathrm{L}, \mathrm{pH}=6.0$. The deionized water, $\mathrm{HCl} 10^{-5} \mathrm{M}$, and $\mathrm{Na}_{2}$ EDTA $0.08 \mathrm{mM}$ solution were used as the stripping phase. Transport process was done by placing of metal ion solution ( $25 \mathrm{mg} / \mathrm{L}$ ) into the source phase chamber and $50 \mathrm{~mL}$ deionized water into the stripping phase chamber, and strirred (150 rpm) at room temperature, the transport test for 24 hours. Afterward deionized water was replaced by $\mathrm{HCl} 10^{-5} \mathrm{M}$ and $\mathrm{Na}_{2}$ EDTA $0.08 \mathrm{mM}$ solution. The concentration of metal ion present in the source and stripping phases were analyzed using Atomic absorption spectroscopy (Perkin- Elmer AA200).

\section{RESULTS AND DISCUSSION}

\section{A. Characteristics Membrane}

Effect of the PEG addition on the tensile strength, elongation percentage and Modulus young of the chitosan-silica membrane is expressed in Table I, showing that blending with PEG changes the properties of the membrane. The tensile strength tends to decline with addition of PEG $0.5 \mathrm{~g}$ and more than that mass shows constant in the tensile strength. It may be attributed to the strong inner-stress existing in the membrane [9]. Mass ratio of chitosan/silica/PEG 1:0.8:0.5 have maximum percent Elongation and minimum Young's modulus, it is indicated that membrane strong and flexible.

TABLE I: TENSILE STRENGTH, PERCENT ELONGATION AND MODUlus YOUNG OF CH/Si/P MEMBRANE

\begin{tabular}{llll}
\hline $\begin{array}{l}\text { Membrane } \\
\begin{array}{l}\text { Composition } \\
\text { (chitosan:silica:PEG, } \\
\text { in g) }\end{array}\end{array}$ & $\begin{array}{l}\text { Tensile } \\
\text { Strength } \\
(\mathrm{MPa})\end{array}$ & \% Elongation & $\begin{array}{l}\text { Modulus } \\
\text { Young }\end{array}$ \\
\hline $1: 0$ & $24.1 \pm 1.1$ & $19.7 \pm 0.1$ & 122.3 \\
$1: 0.8$ & $24.4 \pm 1.0$ & $19.0 \pm 0.2$ & 128.4 \\
$1: 0.8: 0.5$ & $16.5 \pm 0.9$ & $20.5 \pm 0.4$ & 80.5 \\
\hline
\end{tabular}

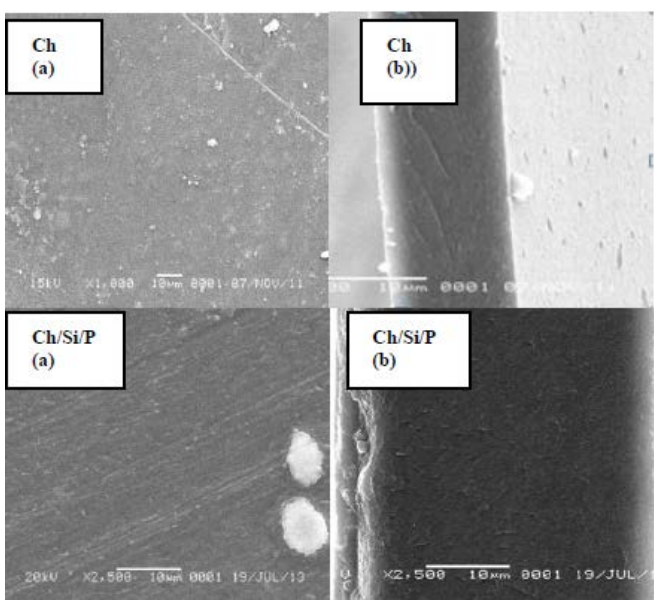

Fig. 2. SEM images of the $\mathrm{Ch}$ and $\mathrm{Ch} / \mathrm{Si} / \mathrm{P}$ membranes: (a) Surface, (b) Cross section.

Fig. 2(a) and Fig. 2(b) surface and cross section image Ch membrane showed that dense membrane. The addition of silica and PEG into chitosan membrane (Ch) resulted in the pores increases. The calculation of the value of the pore size distribution using SEM photograph with a computer program Image $J$ as performed by [11], [12]. Ch/Si/P membrane has an average value of pore size $1.9 \mu \mathrm{m}$.

Fig. 3 presents the swelling capability represented by swelling index (\%) of the membranes. The sensitivity of the membrane toward $\mathrm{pH}$ is from the nature of chitosan. Hydrophilicity of the membrane increases with the addition of PEG and decreases with the addition of silica. In general, the modifying with silica and PEG influenced the physical properties and water adsorption [9].

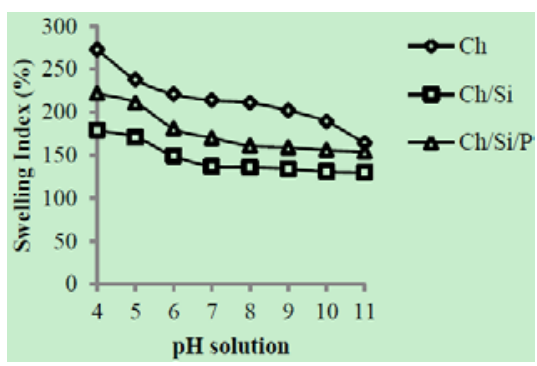

Fig. 3. Plot of swelling index (\%) for $\mathrm{Ch}, \mathrm{Ch} / \mathrm{Si}$, and $\mathrm{Ch} / \mathrm{Si} / \mathrm{P}$ membranes in a buffer solution with various pHs. 


\section{B. Binary Component Adsorption Result}

Fig. 4(a) and Fig. 4(b) show the adsorption and desorption (permeated) of binary copper and zinc ions onto $\mathrm{Ch} / \mathrm{Si} / \mathrm{P}$ membranes in various phase stripping solution. In the water, $\mathrm{HCl}$ and $\mathrm{Na}_{2}$ EDTA as phase stripping solution, adsorption $\mathrm{Cu}(\mathrm{II})>\mathrm{Zn}(\mathrm{II})$. The ions $\mathrm{Cu}(\mathrm{II})$ and $\mathrm{Zn}(\mathrm{II})$ are an intermediate acid according to the HSAB concept, so the two ions have the same tendency to bind with $-\mathrm{NH}_{2}$ [13]. The amount of ions were adsorbed on the medium to follow the order of water $>\mathrm{HCl}>\mathrm{Na}_{2}$ EDTA, and vice versa permeated ions in $\mathrm{Na}_{2} \mathrm{EDTA}>\mathrm{HCl}>$ water. It indicates that the stability of the complex compounds formed between ions with $-\mathrm{NH}_{2}$ greater in $\mathrm{Na}_{2}$ EDTA medium compared with water and $\mathrm{HCl}$. The $\mathrm{Na}_{2}$ EDTA is a chelating agent that is strong compared with $\mathrm{HCl}$ and water. These results can be explained that the formation of complex compounds with metal ions $-\mathrm{NH}_{2}$ largely through the formation of complex compounds with $\mathrm{Na}_{2}$ EDTA relatively stable so difficult to be released again. In $\mathrm{HCl}$ medium, the formation of complex compounds made possible through the mechanism of the formation of hydrogen bonds are less stable so that the metal ion be easily detached [14]. The amount of $\mathrm{Cu}(\mathrm{II})$ adsorbed greater than $\mathrm{Zn}(\mathrm{II})$, this can be explained by the ionic radii of metal ions. This fact can be correlated with the ionic radii: $\mathrm{Cu}(\mathrm{II})<$ $\mathrm{Zn}(\mathrm{II})$. This resulted in the environment around the $\mathrm{Zn}(\mathrm{II})$ is more crowded than $\mathrm{Cu}(\mathrm{II})$, so that the $\mathrm{Cu}(\mathrm{II})$ more easily bind to the active groups on the membrane. Thus the complex compounds of $\mathrm{Cu}$ (II)- $\mathrm{NH}_{2}$ in the membrane more stable than $\mathrm{Zn}(\mathrm{II})-\mathrm{NH}_{2}$. These data are supported by the value of the equilibrium constant of the first formation of metal complexes with ligands $\mathrm{NH}_{3}\left(\mathrm{~K}_{1}\right) 4.04$ and 2.21 for $\mathrm{Cu}(\mathrm{II})$ and $\mathrm{Zn}(\mathrm{II})$, respectively [15]. The larger the value of $\mathrm{K}_{1}$, the more stable complex compounds formed.

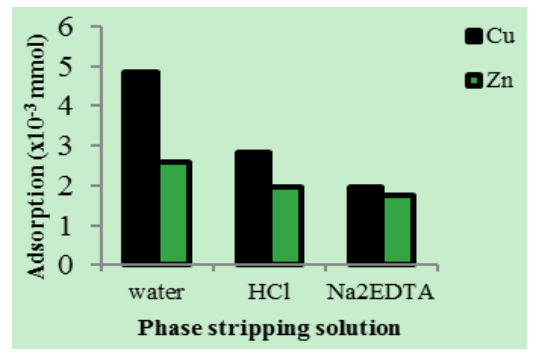

(a)

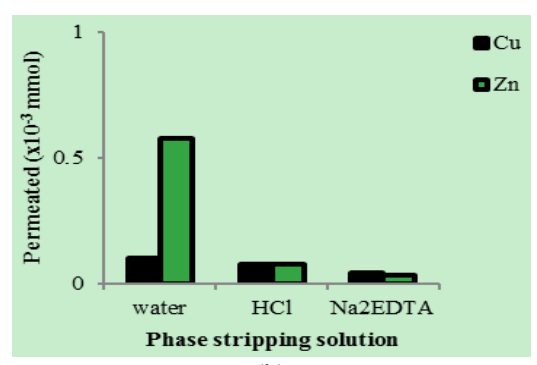

(b)

Fig. 4. (a) Adsorption and (b) Permeated mixtures $\mathrm{Cu}(\mathrm{II})$ and $\mathrm{Zn}$ (II) ions onto $\mathrm{Ch} / \mathrm{Si} / \mathrm{P}$ membrane in various phase stripping solution.

\section{CONCLUSIONS}

Chitosan-silica-PEG membrane $(\mathrm{Ch} / \mathrm{Si} / \mathrm{P})$ has been successfully synthesized. Blending chitosan with polyethylene glycol and silica enhances adsorption behaviour probable due to pore size and water affinity of membrane. $\mathrm{Cu}(\mathrm{II})$ is the best ion to form complex with the $\mathrm{Ch} / \mathrm{Si} / \mathrm{P}$ membrane compared to $\mathrm{Zn}(\mathrm{II})$ The competition in binary mixture revealed a complex phenomenon. The presence of zinc ion in the mixture has a more significant impact on the copper adsorption. Desorption results showed that it was possible to separate copper from zinc using water, $\mathrm{HCl}$, and $\mathrm{Na}_{2}$ EDTA solution for $\mathrm{Cu}$ and $\mathrm{Zn}$ recovery. $\mathrm{Ch} / \mathrm{Si} / \mathrm{P}$ membrane can mainly find application in the field of separation sciences.

\section{ACKNOWLEDGMENT}

The author highly appreciates the Indonesian Higher Education Departement for the financial support through scholarship for doctorate program in Gadjah Mada University.

\section{REFERENCES}

[1] G. M. Shariaty-Niassar, J. Barzin, and T. Matsuura, "Effect of chitosan membrane morphology on copper ion adsorption," Chemical Engineering Journal, vol. 165, pp. 46-55, 2010.

[2] S. R. Viera and M. M. Beppu, "Dynamic and static adsorption and desorption of $\mathrm{Hg}(\mathrm{II})$ ions on chitosan membranes and spheres," Water Research, vol. 40, pp. 1726-1734, 2006.

[3] S. R. Viera, E. Guibal, E. A. Silva, and M. M. Beppu, "Adsorption and desorption of binary mixtures of copper and mercury ions on natural and crosslinked chitosan membranes," Adsorption, vol. 13, pp. 603-611, 2007.

[4] G. Z. Kyzas, P. I. Siafaka, E. G. Pavlidou, and K. J. Chrissafis, "Synthesis and adsorption application of succinyl-grafted chitosan for simultanneous removal of zinc and cationic dye from binary hazardous mixtures,” Chemical Engineering Journal, vol. 259, pp. 438-448, 2015.

[5] A. R. Cestari, F. S. V. Eunice, and R. S. M Charlene, “Thermodynamics of the $\mathrm{Cu}(\mathrm{II})$ adsorption on thin vanillin-modified chitosan membranes," Journal Chemical Thermodynamics, vol. 38, pp. 1092-1099, 2006.

[6] E. Salehi et al., "Novel chitosan/poly(vinyl) alcohol thin adsorptive membranes modified with amino functionalized multi-walled carbon nanotubes for $\mathrm{Cu}(\mathrm{II})$ removal from water: Preparation, characterization," Adsorption Kinetics and Thermodynamics, Separation Purification Technology, vol. 89, pp. 309-319, 2012.

[7] E. Salehi and S. S. Madaeni, "Influence of poly(ethylene glycol) as pore-generator on morphology and performance of chitosan/poly(vinyl alcohol) membrane adsorbents,” Applied Surface Science, vol. 288, pp.537-541, 2014.

[8] X. Liu, Z., Cheng, and W. Ma, "Removal of copper by modified chitosan adsorptive membrane,” Frontiers Chemical Engineering China, vol. 3, no. 1, pp. 102-106, 2009.

[9] F. W. Mahatmanti, Nuryono, and Narsito. "Pysichal characteristics of chitosan based film modified with silica and polyethylene glycol," Indonesian Journal of Chemistry, vol. 14, no. 2, pp. 131-137, 2014.

[10] A. A. Kiswandono, D. Siswanto, N. H. Aprilita, and S. J. Santosa, "Transport of phenol through inclusion polymer membrane (PIM) using copoly(eugenol-DVB) as membrane carriers," Indonesian Journal of Chemistry, vol. 12, no. 2, pp. 105-112, 2012.

[11] D. E. S. Santos et al., "Chitosan macroporous asymetric membranes-preparation, characterization and transport drugs,” Journal Membrane Science, vol. 325, pp. 362-370, 2008.

[12] R. Ziel, A. Haus, and dan A. Tulke, "Quantification of the pore size distribution (porosity profiles) in microfiltration membranes by SEM, TEM and computer image analysis,” Journal Membrane Science, vol. 323, pp. 241-246, 2008.

[13] R. G. Pearson, "Hard and soft acids and bases," Journal American Chemical Society, vol. 85, pp. 3533-3543, 1963.

[14] B. Krajewska, "Diffusion of metal ions through gel chitosan membranes,” Reactive \& Functional Polymers, vol. 47, pp. 37-47, 2001.

[15] A. E. Martell and R. D. Hancock, Metal Complexes in Aqueous Solutions, New York: Plenum Press, 1996, p. 48. 


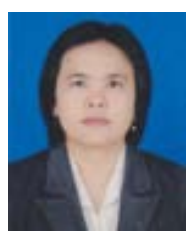

F. Widhi Mahatmanti was born in Central Java Province, Indonesia, in December 1969. She received her Strata-1 degree in chemistry program at Diponegoro University in 1993. She obtained her M.Sc at Gadjah Mada University in 2001. Since 1997 until now a lecturer in the Chemistry Department, Faculty of Mathematics and Natural Sciences at the Semarang State University, Indonesia. Since 2011 until now, she has been the doctoral student (chemistry program) at the University of Gadjah Mada.
She wrote some article: Synthesis and properties of porous membrane from chitosan/SiO2/polyethylene glycol hybrid materials, in Proceeding of the 1s International Pharmacy Conference on Research and Practice Toward Excellent In Natural Products: Preserving Traditions, Embracing innovations, UII Yogyakarta, 13 November 2012, 15-20; Synthesis of chitosan-silica film using sodium silicate from rice hull ash, Proceeding of the 2nd International Conference of the Indonesian Chemical Society, UII Yogyakarta, 22-23 October 2013, 202-206; Physical Characteristics of Chitosan based Film Modified with Silica and polyethylene glycol, Indonesian Journal of Chemistry, 14(2), 131-137. 